\title{
Estimating Weibull Parameters for Wind Energy Applications Using Seven Numerical Methods: Case studies of Three Coastal Sites in West Africa
}

\author{
Agbassou Guenoukpati a, Adekunlé Akim Salamia*, Mawugno Koffi Kodjoa ${ }^{a}$ Kossi \\ $\mathrm{Napo}^{\mathrm{b}}$
}

${ }^{a}$ Laboratoire de Recherche en Sciences de l'Ingénieur (LARSI), Department of Electrical Engineering, Ecole Nationale Supérieure d'Ingénieurs (ENSI), University of Lomé, BP 1515, Lomé, Togo

${ }^{\mathrm{b}}$ Laboratoire sur l'Energie Solaire (LES), Faculté Des Sciences (FDS) ), University of Lomé, BP 1515, Lomé, Togo

\begin{abstract}
In this study, the effectiveness of seven numerical methods is evaluated to determine the shape (K) and scale (C) parameters of Weibull distribution function for the purpose of calculating the wind speed characteristics and wind power density. The selected methods are graphical method (GPM), empirical method of Justus (EMJ), empirical method of Lysen (EML), energy pattern factor method (EPFM), maximum likelihood method (MLM) moment method (MOM) and the proposed. Hybrid method (HM) derived from EPFM and EMJ. The purpose is to identify the most appropriate method for computing the mean wind speed, wind speed standard deviation and wind power density for different costal locations in West Africa. Three costal sites (Lomé, Accra and Cotonou) are selected. The input data was collected, from January 2004 to December 2015 for Lomé site, from January 2009 to December 2015 for Accra site and from January 2009 to December 2012 for Cotonou. The results indicate that the precision of the computed mean wind speed, wind speed standard deviation and wind power density values change when different parameters estimation methods are used. Five of them which are EMJ, EML, EPF, MOM, ML, and HM method present very good accuracy while GPM shows weak ability for all three sites. O2020. CBIOREIJRED. All rights reserved
\end{abstract}

Keywords: Modeling, Histogram of wind speed distribution, Weibull parameters estimation methods, Comparative evaluation.

Article History: Received: 21 ${ }^{\text {st }}$ April 2019; Received: $1^{\text {st }}$ January 2020; Accepted: 19th February 2020; Available online: $4^{\text {th }}$ May 2020 How to Cite This Article: Guenoukpati, A., Salami, A.A., Kodjo, M.K., and Napo, K. (2020) Estimating Weibull Parameters for Wind Energy Applications Using Seven Numerical Methods: Case studies of Three Coastal Sites in West Africa. International Journal of Renewable Energy Development, $9(2), 217-226$

https://doi.org/10.14710/ijred.9.2.217-226

\section{Introduction}

Nowadays, West Africa faces the challenge of generating more electricity to meet existing and future demand in a sustainable way (Brew-Hammond and Kemausuor 2009; Deichmann et al. 2011). Wind is an inexhaustible resource whose energy utilization has been increasing around the world at an accelerating pace while the development of new wind projects continues to be hampered by the lack of reliable and accurate wind resource data in many parts of the world, especially in the developing countries (Ayenagbo, Kimatu, and Rongcheng 2011; Mentis et al. 2015).

Commonly used functions for fitting the measured wind speed probability distribution in a given location over a certain period of time, typically monthly or yearly, are the Weibull, the Rayleigh and Lognormal. Amongst the most common distribution models, the Weibull function is accepted as the best model. Weibull distribution, a particular case of the generalized gamma distribution law, is characterized by the shape parameter
$\mathrm{K}$ and the scale parameter $\mathrm{C}$. The two Weibull parameters help determine wind characteristics. Thus, the various estimation methods for Weibull parameters have been proposed. Justus et al. (Justus et al. 1978) presented the four different estimation methods and the GPM (graphical method) based on the concept of least squares method and also compared them. Stevens and Smulders (Stevens, M. J. M., \& Smulders 1979) suggested the MLM (maximum likelihood method) for the estimation of the parameters of Weibull wind speed distribution. Seguro and Lambert (Seguro and Lambert 2000) compared the commonly-used (MLM), (GPM) and the proposed MMLM (modified maximum likelihood method). As a result, they concluded that MLM performs better than GPM. Dorvlo (Dorvlo 2002) estimated the Weibull parameters used to model wind speeds in Oman using three methods, the Chi-square method, moment method (MOM) and GPM. The results showed that the Chi-square method gives better estimates for Weibull parameters than the other methods. Rocha et al. (Rocha et al. 2012) studied seven methods GPM, MLM, MMLM, MOM, EPFM, EM and

\footnotetext{
* Corresponding author: akimsalami11@gmail.com
} 
EEM (equivalent energy method). They aimed to analyze and compare these seven numerical methods for assessing effectiveness in determining parameters of Weibull, using wind data collected in the northeast region of Brazil. Jowder (Jowder 2009) compared the EM (empirical method) and GPM for prediction of the average wind speed and power density, using wind data measured in the Kingdom of Bahrain. The results indicated that EM provides more accurate prediction than GPM. Akdag and Dinler (Akdağ, S. A., \& Dinler 2009) used three conventional methods, namely GPM, MLM and MOM to compare the proposed EPFM (energy pattern factor method) for estimating Weibull parameters. Their results show that the EPFM has better suitability than others according to power density and mean wind speed. Furthermore, Chang conducted a comparative study to show the performance of GPM, MLM, MMLM, MOM, EPFM and EM, in estimating Weibull parameters for wind energy application (Chang 2011). Along the same lines, Azad et al. (Azad, A., Rasul, M., \& Yusaf 2014) used the seven methods applied by Rocha et al. (Rocha et al. 2012) to estimate Weibull parameters and used six statistical tools to rank the methods precisely. They found that MOM and MLM are the most efficient methods for estimating parameters of Weibull distribution. In addition, Arslan et al (Arslan, Bulut, and Yavuz 2014) compared MOM, MLM and the LMOM (L-moment method) for estimation of wind speed parameters relevant to Weibull distribution. They also found that when the sample size is greater than 100, MLM is preferable in comparison to other methods for the estimation of shape parameter in terms of the MSE (mean square error) criteria.

Assessing the existing numerical methods to determine the most appropriate one for estimating of Weibull parameters is truly important in different applications of wind energy. Nevertheless, to the best of our knowledge, there is a lack of study in the literature on determining the most accurate Weibull parameter estimation methods to fit wind speed probability distribution histograms. Consequently, in this study, we evaluate the capability of six methods in estimating the $\mathrm{K}$ and $\mathrm{C}$ parameters of Weibull distribution function.

The chief goal of this work is to identify the most appropriate method for fitting wind speed probability distribution histograms for wind energy applications at different locations of West Africa. To achieve this, a comprehensive statistical analysis based upon several statistical parameters and approaches applied for three costal sites in West Africa: Lomé (Togo), Accra (Ghana) and Cotonou (Benin) is conducted among six well known methods namely GPM, EMJ, EML, EPFM, MLM MOM and the proposed Hybrid method (HM) derived from EPFM and EMJ.

The rest of this paper is structured as follows: the wind speed data of each site is presented in Section 2. Section 3 describes methods for calculation of Weibull parameters. In Section 4, statistical indicators for performance evaluation are illustrated. In Section 5, results and discussion are presented. Finally, conclusion is drawn in Section 6.

\section{The data}

The data is saved every day at one hour interval (this is the average over the 10 minutes before the hour) at a height of $10 \mathrm{~m}$ above the ground. Note that the measuring point of these weather data for each station is in an airport area which theirs coordinates are presented in Table 1. Data collected cover the period, from January 2004 to December 2015 for Lomé site (record length of approximately twelve (12) years), from January 2009 to December 2015 for Accra site (record length of approximately seven (7) years) and from January 2009 to December 2012 for Cotonou site (record length of approximately four (4) years).

Table 1

Coordinates of the case study site

\begin{tabular}{lc}
\hline Sites & Coordinates \\
\hline Accra (Kotoka) & $5.60 \mathrm{~N}, 0.17 \mathrm{~W}, 69$ meters \\
Cotonou (Cadjehoun) & $6.35 \mathrm{~N}, 2.38 \mathrm{E}, 9$ meters \\
Lomé (Tokoin) & $6.17 \mathrm{~N}, 1.25 \mathrm{E}, 25$ meters \\
\hline
\end{tabular}

Table 2 presents statistical parameters and the mean power density for the three (03) studied sites, (Lomé site, Accra site, and Cotonou site). As noticed, Accra site has the highest mean wind speed with the value of $4.1603 \mathrm{~m} / \mathrm{s}$ and Lomé site has the lowest wind speed with the value of $3.5287 \mathrm{~m} / \mathrm{s}$. According to values of mean power density $\left(<100 \mathrm{~W} / \mathrm{m}^{2}\right)$ obtained in Table 2 we concluded that the three sites are not suitable for large-scale electric wind application (Celik 2003; Keyhani et al. 2010). But, smallscale wind turbines could be good option for the three sites (Lomé, Accra and Cotonou sites) in order to supply power for lightings, electric fans, chargers and air conditioning units for small houses (Mostafaeipour et al. 2011).

Figures 1 to 3 offer respectively the probability and cumulative probability densities of the utilized wind speed data for selected sites. The descriptive statistics presented in Table 2 as well as the probability and cumulative probability distribution of the wind speed provided by that figures give a good insight on the characteristics of wind speed in the selected site.

\section{Methods for calculation of Weibull parameters}

The wind speed measurement data obtained on a site are often vague to provide a clear vision of the wind power potential available on it. Hence, there is a need to compute key parameters that allow a quick assessment of power characteristics hidden in the measured wind speed data(Genc et al. 2005; Lu, Yang, and Burnett 2002; Salami et al. 2013). Since wind is a stochastic valued event, it is better to describe the variation of wind speeds by a statistical function. The probability distribution function (pdf) of the two-parameter Weibull distribution (Equation (1)) is often used in characterizing the distribution of wind speeds measured frequently over a period of a month, a year, or several years (Ajavon et al. 2015; Safari 2011). 
Table 2

Descriptive statistics of the used wind speed data according to geographical locations

\begin{tabular}{llcccccc}
\hline Sites & Periods & $\begin{array}{c}\text { Maximum } \\
\text { wind speed } \\
(\mathrm{m} / \mathrm{s})\end{array}$ & $\begin{array}{c}\text { Mean wind } \\
\text { speed } \\
(\mathrm{m} / \mathrm{s})\end{array}$ & $\begin{array}{l}\text { Standard } \\
\text { deviation } \\
(\mathrm{m} / \mathrm{s})\end{array}$ & $\begin{array}{c}\text { Power } \\
\text { density } \\
\left(\mathrm{W} / \mathrm{m}^{2}\right)\end{array}$ & Kurtosis & Skewness \\
\hline Lomé & $2004-2015$ & 16 & 3.52870 & 2.02964 & 54.96667 & 2.33358 & 0.26247 \\
Accra & $2009-2015$ & 21 & 4.16032 & 2.21591 & 82.22761 & 2.76699 & 0.08801 \\
Cotonou & $2009-2012$ & 14 & 4.01159 & 1.81438 & 63.35978 & 2.49218 & -0.12249 \\
\hline
\end{tabular}
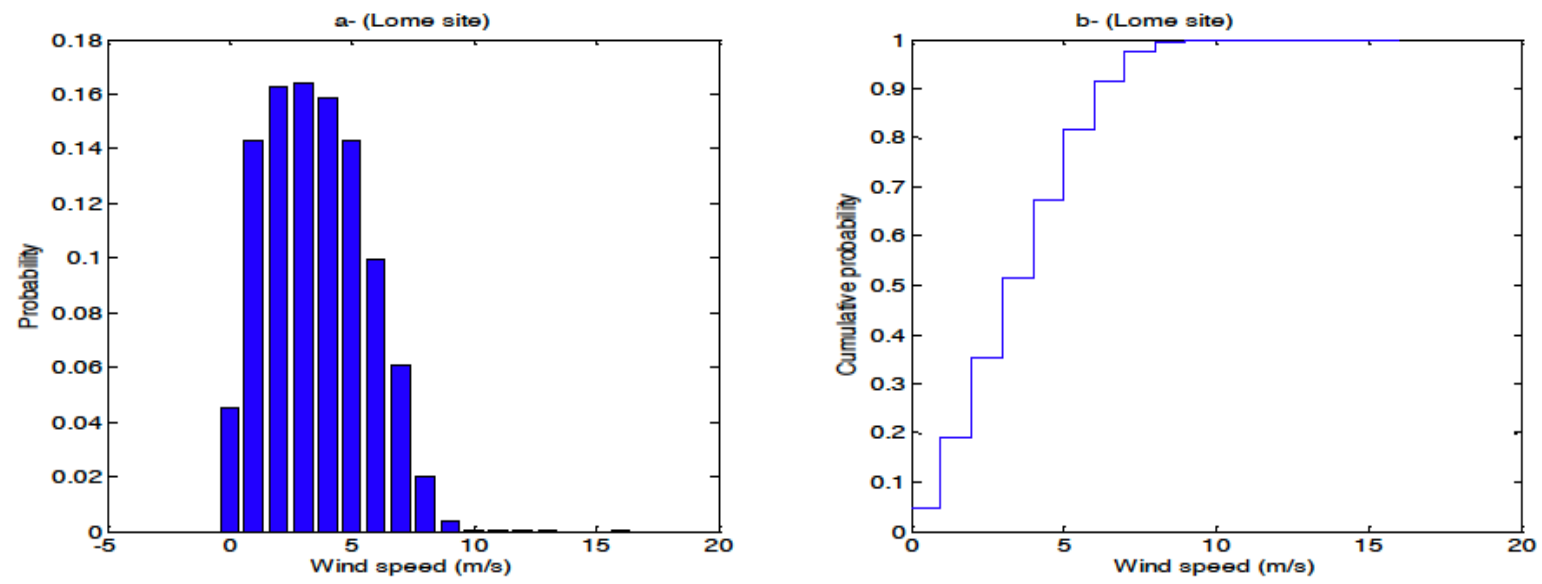

Fig. 1 Probability (a) and cumulative probability (b) densities of the measured wind speed at $10 \mathrm{~m}$ for Lome site
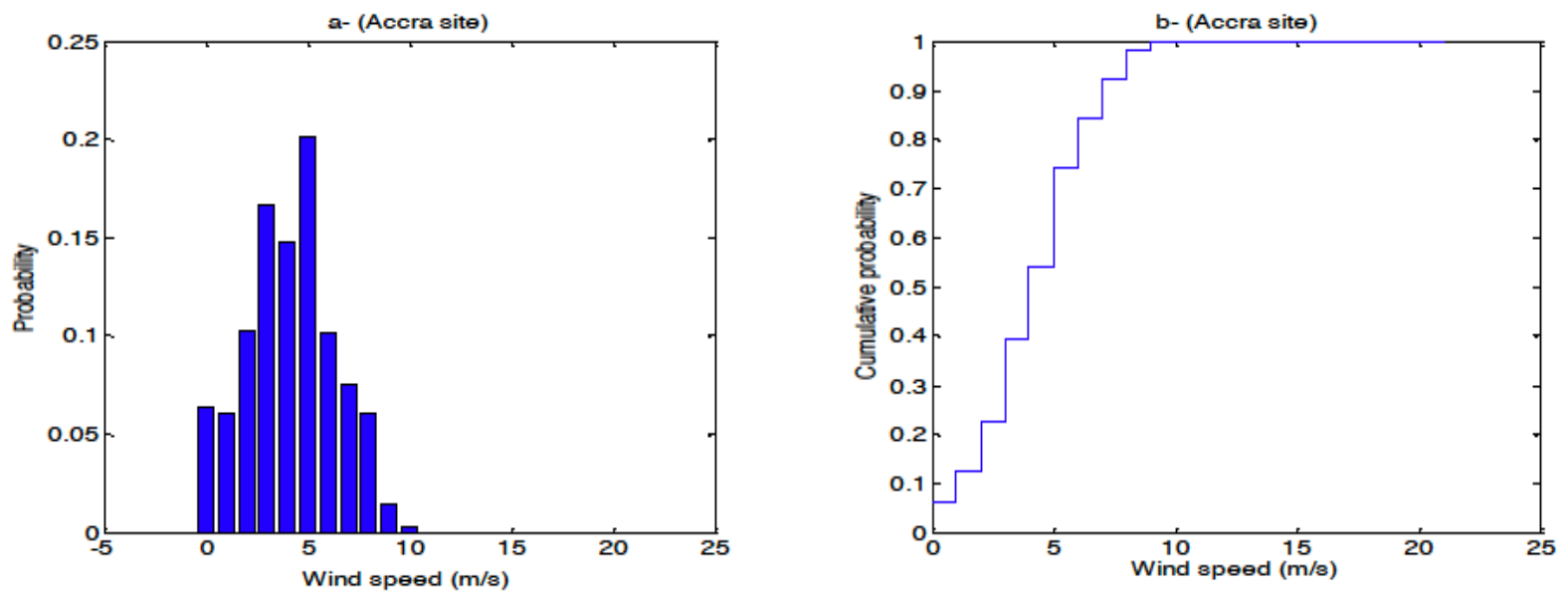

Fig. 2 Probability (a) and cumulative probability (b) densities of the measured wind speed at $10 \mathrm{~m}$ for Accra site
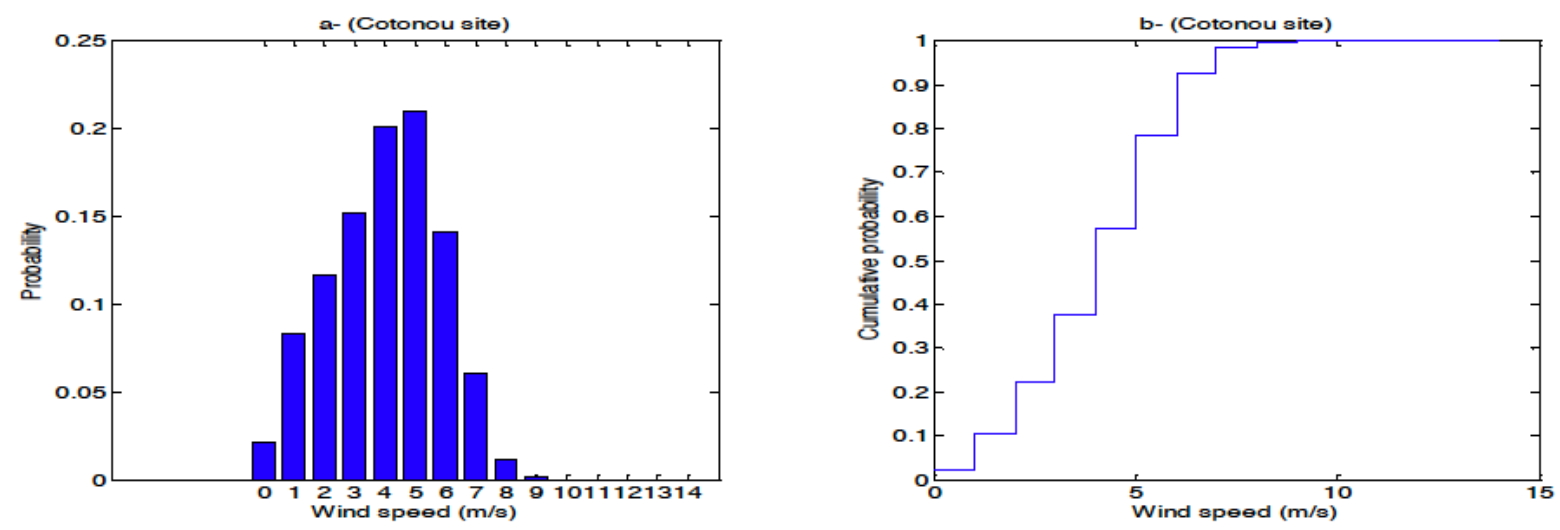

Fig. 3 Probability (a) and cumulative probability (b) densities of the measured wind speed at $10 \mathrm{~m}$ for Cotonou site 


$$
f(V)=\left(\frac{K}{C}\right)\left(\frac{V}{C}\right)^{K-1} \cdot \exp \left[-\left(\frac{V}{C}\right)^{K}\right]
$$

Equation (2) gives the cumulative distribution function (cdf) of the wind speed,

$$
\mathrm{F}(\mathrm{V})=\left(1-\exp \left[-\left(\frac{\mathrm{V}}{\mathrm{C}}\right)^{\mathrm{K}}\right]\right)
$$

The mean and standard deviation of the wind speed series are given by Equations (3) and (4):

$$
\begin{aligned}
& \overline{\mathrm{V}}=\frac{1}{\mathrm{n}} \sum_{\mathrm{i}=1}^{\mathrm{n}} \mathrm{V}_{\mathrm{i}}=\mathrm{C} \cdot \Gamma\left(1+\frac{1}{\mathrm{~K}}\right) \\
& \sigma=\left[\frac{1}{\mathrm{n}-1} \sum_{\mathrm{i}=1}^{\mathrm{n}}\left(\mathrm{V}_{\mathrm{i}}-\overline{\mathrm{V}}\right)\right]^{1 / 2}=\mathrm{C} \cdot\left[\Gamma\left(1+\frac{2}{\mathrm{~K}}\right)-\Gamma^{2}\left(1+\frac{1}{\mathrm{~K}}\right)\right]^{1 / 2}
\end{aligned}
$$

where:

- $\overline{\mathrm{V}}$ is the mean wind speed,

- $\sigma$ is the standard deviation of the observed data of the wind speed,

- $\quad \Gamma$ is the gamma function defined by the Euler integral of the second kind.

The wind power density is an important indicator to determine the potential of wind resources and to describe the amount of wind energy at various wind speed values in a particular location. The knowledge of wind power density is also useful to evaluate the performance of wind turbines and nominate the optimum wind turbines. Wind power density represents the amount of energy available on the site which can be converted to electricity by using wind turbines. Indeed, the mean kinetic energy, available on a site per unit time and per unit area is expressed by Equation (5) (Celik 2003):

$$
\mathrm{P}=\frac{1}{2} \rho \int_{0}^{+\infty} \mathrm{V}^{3} \mathrm{f}(\mathrm{V}) \mathrm{dv}=\frac{1}{2} \rho \overline{\mathrm{V}^{3}}=\frac{1}{2} \rho \mathrm{C}^{3} \Gamma\left(1+\frac{3}{\mathrm{~K}}\right)
$$

where:

- $\quad \rho$ is the air density $\left(\mathrm{kg} \cdot \mathrm{m}^{-3}\right)$,

- $\mathrm{V}$ is the wind speed and,

- $\mathrm{f}(\mathrm{V})$ is the probability distribution function (pdf) of Weibull (Equation (1)),

- $\quad \overline{\mathrm{V}^{3}}$ is the cubic mean wind speeds.

There are some methods introduced in the literature to calculate the $\mathrm{K}$ and $\mathrm{C}$ parameters of Weibull distribution function. In this study, we introduced a Hybrid method
(HM) derived from EPFM and EMJ. Seven methods including graphical method (GPM), empirical method of Justus (EMJ), empirical method of Lysen (EML), energy pattern factor method (EPFM), maximum likelihood method (MLM), moment method (MOM) and Hybrid method (HM) are selected for comparative evaluation. The descriptions of these seven methods are provided briefly in the following.

\subsection{Graphical method (GPM)}

The graphical method is achieved through the cumulative distribution function. In this distribution method, the wind speed data are interpolated by a straight line, using the concept of least squares. The Equation for this method can be represented by a double logarithmic transformation (Celik 2003; Dorvlo 2002) as follows:

$$
\ln \{-\ln [1-\mathrm{F}(\mathrm{V})]\}=\mathrm{K} \ln (\mathrm{V})-\mathrm{K} \ln (\mathrm{C})
$$

\subsection{Empirical method of Justus (EMJ)}

Based on the empirical method introduced by Justus (Justus et al. 1978), the $\mathrm{K}$ and $\mathrm{C}$ parameters are computed, respectively by Equations (7) and (8) as:

$$
\begin{aligned}
& \mathrm{K}=\left(\frac{\sigma}{\overline{\mathrm{V}}}\right)^{-1.086} \\
& \mathrm{C}=\frac{\overline{\mathrm{V}}}{\Gamma\left(1+\frac{1}{\mathrm{~K}}\right)}
\end{aligned}
$$

\subsection{Empirical method of Lysen (EML)}

In the empirical method suggested by Lysen, $\mathrm{K}$ is calculated by Equation (7) as in the Justus method. In fact, the only difference is the Equation of $\mathrm{C}$. In the empirical method of Lysen, $\mathrm{C}$ is obtained by Equation (9):

$C=\bar{V} \cdot\left(0.568+\frac{0.433}{K}\right)^{-\frac{1}{K}}$

\subsection{Energy pattern factor method (EPFM)}

The energy pattern factor method is related to the averaged data of wind speed and is defined by the following Equations (Seguro and Lambert 2000):

$$
\begin{aligned}
& \mathrm{E}_{\mathrm{pf}}=\left(\frac{\overline{\mathrm{V}^{3}}}{\overline{\mathrm{V}}^{3}}\right) \\
& \mathrm{K}=\left(1+\frac{3.69}{\mathrm{E}_{\mathrm{pf}}^{2}}\right)
\end{aligned}
$$

C parameter is also computed similar to empirical method of Justus by Equation (8). 


\subsection{Maximum likelihood method (MLM)}

The maximum likelihood estimation method is difficult to solve, since numerical iterations are needed to determine the parameters of the Weibull distribution (Chang 2011; Salami et al. 2013). In this method, the parameters $\mathrm{K}$ and $\mathrm{C}$ are determined according to the Equations below (Dorvlo 2002):

$\mathrm{K}=\left[\left[\frac{\sum_{\mathrm{i}=1}^{\mathrm{n}} \mathrm{V}_{\mathrm{i}}^{\mathrm{K}} \ln \left(\mathrm{V}_{\mathrm{i}}\right)}{\sum_{\mathrm{i}=1}^{\mathrm{n}} \mathrm{V}_{\mathrm{i}}^{\mathrm{K}}}\right]-\left[\frac{\sum_{\mathrm{i}=1}^{\mathrm{n}} \ln \left(\mathrm{V}_{\mathrm{i}}\right)}{\mathrm{n}}\right]\right]^{-1}$

$\mathrm{C}=\left[\frac{\sum_{\mathrm{i}=1}^{\mathrm{n}} \mathrm{V}_{\mathrm{i}}^{\mathrm{K}}}{\mathrm{n}}\right]^{1 / \mathrm{K}}$

\subsection{Moment method (MOM)}

The moment method can be used as an alternative to the maximum likelihood method (Rocha et al. 2012) and, in this case, the parameters $\mathrm{K}$ and $\mathrm{C}$ are determined by the following Equations:

$$
\begin{aligned}
& \overline{\mathrm{V}}=\mathrm{C} \cdot \Gamma\left(1+\frac{1}{\mathrm{~K}}\right) \\
& \sigma=\mathrm{C} \cdot\left[\Gamma\left(1+\frac{2}{\mathrm{~K}}\right)-\Gamma^{2}\left(1+\frac{1}{\mathrm{~K}}\right)\right]^{1 / 2}
\end{aligned}
$$

\subsection{Proposed method (Hybrid EPFM-EMJ)}

A hybrid method (HM) derived from EPFM and EMJ permit to find a formula to determine the shape parameter as follows:

$$
\mathrm{K}=\frac{1}{2}\left(1+\frac{3.69}{\mathrm{E}_{\mathrm{pf}}^{2}}+\left(\frac{\sigma}{\overline{\mathrm{V}}}\right)^{-1.086}\right)
$$

and $\mathrm{C}$ parameter is computed similar to empirical method of Justus by Equation (8).

\section{Performance Indicators}

To evaluate the performance of each method, the root mean squared error (RMSE), the correlation coefficient $\mathrm{R}^{2}$ the relative percent error (RPE) and Relative root mean square error (RRMSE) are used.

The RMSE parameter, whose ideal value is zero (0), gives the difference between the predicted or expected value $\mathrm{x}_{\mathrm{i}}$ and observed value $\mathrm{y}_{\mathrm{i}}$ for $\mathrm{N}$ data samples (Akdağ, S. A., \& Dinler 2009; Rocha et al. 2012). It is given by Equation (17)
$\operatorname{RMSE}=\sqrt{\frac{1}{\mathrm{~N}} \sum_{\mathrm{i}=1}^{\mathrm{N}}\left(\mathrm{y}_{\mathrm{i}}-\mathrm{x}_{\mathrm{i}}\right)^{2}}$

The correlation coefficient whose ideal value is one (1) gives the correlation between the predicted or expected and observed values (Leung and Yang 2012; Stevens, M. J. M., \& Smulders 1979). It is given by the relation (18).

$$
R^{2}=\frac{\sum_{i=1}^{N}\left(x_{i}-\overline{x_{i}}\right) \cdot\left(y_{i}-\overline{y_{i}}\right)}{\sqrt{\sum_{i=1}^{N}\left(x_{i}-\overline{x_{i}}\right)^{2} \cdot \sum_{i=1}^{N}\left(y_{i}-\overline{y_{i}}\right)^{2}}}
$$

The relative percent error (RPE) between the predicted value and the observed value is given by Equation (19), it is considered acceptable if its absolute value is less or equal to 10\% (Chang 2011; Dorvlo 2002; Seguro and Lambert 2000).

$$
\operatorname{RPE}(\%)=100 \cdot\left(\frac{y_{i}-x_{i}}{y_{i}}\right)
$$

The RRMSE is obtained by dividing the RMSE of wind speed characteristics (Means, standard deviations and power densities of wind speed) obtained by the average measured values as follows:

$$
\operatorname{RRMSE}(\%)=\frac{\sqrt{\frac{1}{\mathrm{n}} \sum_{\mathrm{i}=1}^{\mathrm{n}}\left(\mathrm{y}_{\mathrm{i}}-\mathrm{x}_{\mathrm{i}}\right)^{2}}}{\frac{1}{\mathrm{n}} \sum_{\mathrm{i}=1}^{\mathrm{n}} \mathrm{y}_{\mathrm{i}}} \cdot 100
$$

Different ranges of RRMSE can be defined to represent the models' precision (Jamieson, Porter, and Wilson 1991; Li et al. 2013; Mohammadi et al. 2016) as:

- Excellent for RRMSE $<10 \%$;

- Good for $10 \%<$ RRMSE $<20 \%$;

- Fair for $20 \%<$ RRMSE $<30 \%$; Poor for RRMSE $>30 \%$.

\section{Results and discussion}

Given the importance of the analysis of monthly and global variations of wind characteristics on a given site, our case study covers a global dataset for each site and each month (the entire dataset is grouped monthly into 12 study periods: January, February, March, April, May, June, July, August, September, October, November, December)

\subsection{Global Analysis}

Our goal in this article is to identify the most appropriate method for fitting wind speed probability distribution histograms for wind energy applications on three costal sites in West Africa: Lomé (Togo), Accra (Ghana) and Cotonou (Benin). From Figures 4, 5 and 6 it is possible to verify how the curves representing the Weibull probability density function, for each of the six numerical methods considered in the analysis, match the histograms, giving an idea of which method yields the best fit to the data of wind speed collected. 
Citation: Guenoukpati, A., Salami, A.A., Kodjo, M.K., and Napo, K. (2020) Estimating Weibull Parameters for Wind Energy Applications Using Seven Numerical Methods: Case studies of Three Coastal Sites in West Africa. Int. Journal of Renewable Energy Development, 9(2),217-226, doi: 10.14710/ijred.9.2.217-226

$\mathrm{P}$ a g e 1222
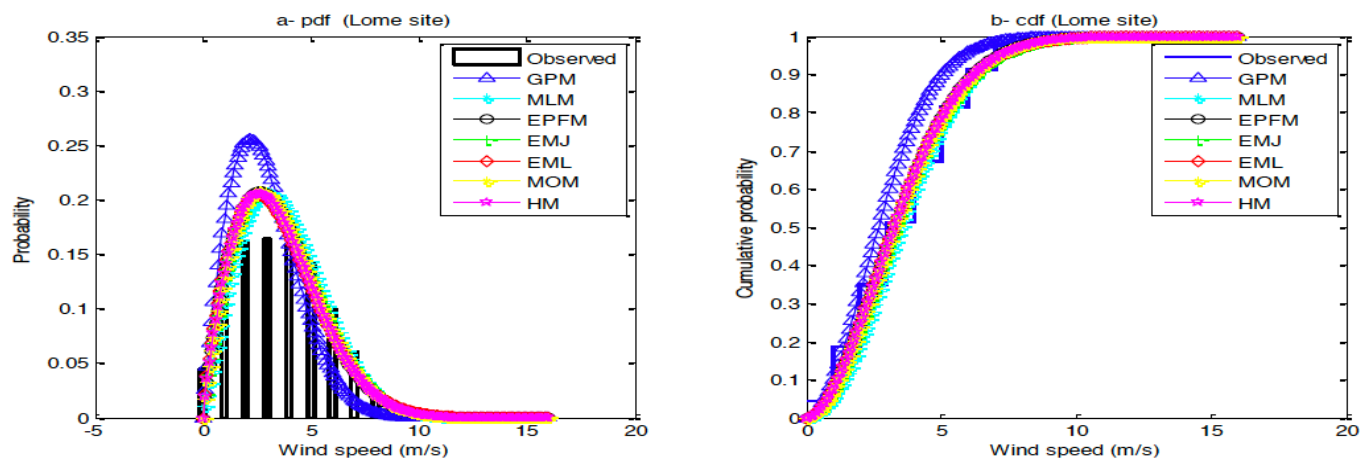

Fig. 4 Weibull distribution (a) and cumulative distribution (b) functions - Lomé (years 2004-2015)
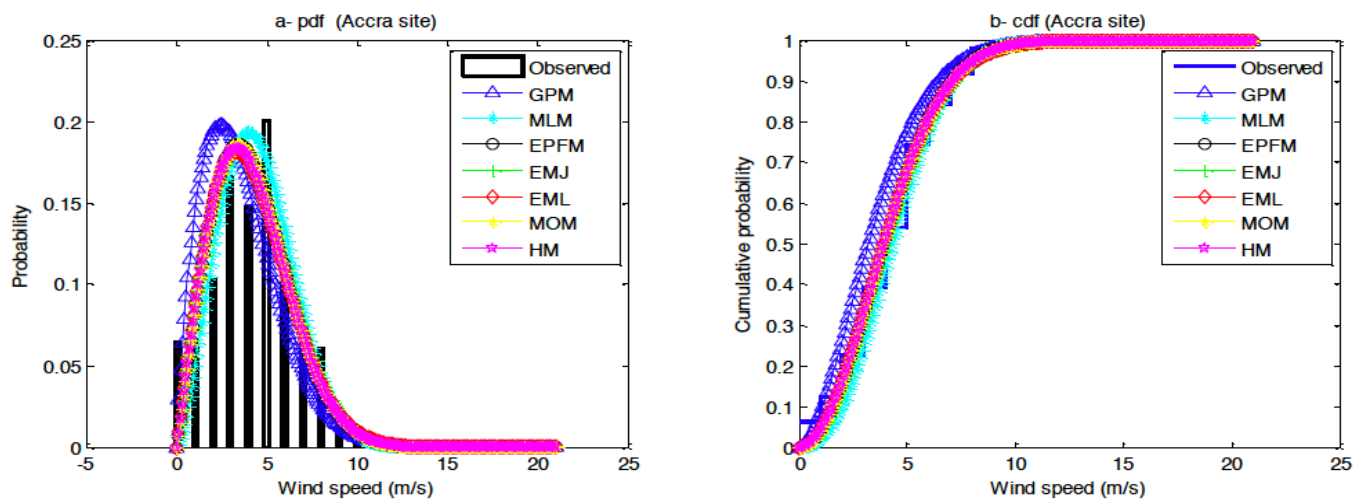

Fig. 5 Weibull distribution (a) and cumulative distribution (b) functions - Accra (years 2009-2012)
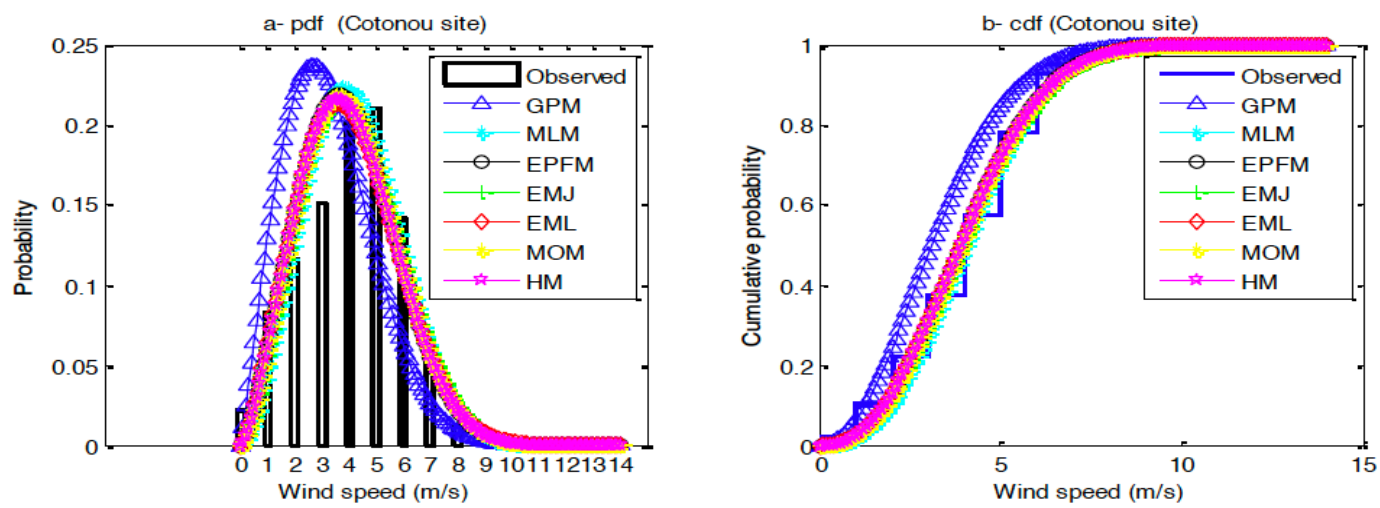

Fig. 6 Weibull distribution (a) and cumulative distribution (b) functions - Cotonou (years 2009-2015)

Graphically, it is observed that six methods (MLM, EPF, EMJ, EML MOM and HM), expected GPM present a better curve fit with the histogram of the wind speed on the three sites. To choose adequate method that adjusts better the histogram of the wind speed on each site, we calculated the RMSE and $\mathrm{R}^{2}$. The results in Table 3 show that:

- on Lomé site, only two methods (EMJ and EML) have RMSE below 0.0200 and $\mathrm{R}^{2}$ which are above 0.9660 . EMJ and EML are followed by HM with RMSE of 0.0203 and $\mathrm{R}^{2}$ of 0.9658 ;
- on Accra site, only MLM and EPFM have RMSE below 0.0210 and $\mathrm{R}^{2}$ which are above 0.9500. MLM and EPFM are followed by HM with RMSE of 0.0241 and $\mathrm{R}^{2}$ of 0.9299 ;

- on Cotonou site, only MLM has RMSE below 0.0210 and $\mathrm{R}^{2}$ which are above 0.9600 . . MLM is followed by HM with RMSE of 0.0224 and $\mathrm{R}^{2}$ of 0.9588 .

The predicted values for $\mathrm{K}$ and $\mathrm{C}$ permitted the computation of the mean wind speed, standard deviation and its mean power density for each method, and the results are presented in Tables 4, 5 and 6 . 
Table 3

Comparison of methods for different sites

\begin{tabular}{|c|c|c|c|c|c|c|c|c|c|c|c|c|}
\hline \multirow[t]{2}{*}{ Methods } & \multicolumn{4}{|c|}{ Lomé } & \multicolumn{4}{|c|}{ Accra } & \multicolumn{4}{|c|}{ Cotonou } \\
\hline & K & $\mathrm{C}$ & RMSE & $\mathrm{R}^{2}$ & $\mathrm{~K}$ & $\mathrm{C}$ & RMSE & $\mathrm{R}^{2}$ & K & $\mathrm{C}$ & RMSE & $\mathrm{R}^{2}$ \\
\hline GPM & 1.8961 & 3.2471 & 0.0407 & 0.9061 & 1.7332 & 3.9821 & 0.0388 & 0.8305 & 2.0705 & 3.7028 & 0.0487 & 0.8219 \\
\hline MLM & 2.0310 & 4.1788 & 0.0213 & 0.9621 & 2.3825 & 5.0172 & 0.0207 & 0.9527 & 2.5722 & 4.6173 & 0.0206 & 0.9670 \\
\hline EPFM & 1.8846 & 3.9755 & 0.0207 & 0.9652 & 2.0616 & 4.6965 & 0.0238 & 0.9329 & 2.4372 & 4.5239 & 0.0224 & 0.9588 \\
\hline EMJ & 1.8233 & 3.9704 & 0.0199 & 0.9662 & 1.9820 & 4.6936 & 0.0245 & 0.9265 & 2.3671 & 4.5264 & 0.0225 & 0.9570 \\
\hline EML & 1.8233 & 3.9732 & 0.0198 & 0.9663 & 1.9820 & 4.6963 & 0.0245 & 0.9266 & 2.3671 & 4.5276 & 0.0225 & 0.9571 \\
\hline MOM & 1.8866 & 3.9756 & 0.0208 & 0.9651 & 2.0636 & 4.6965 & 0.0238 & 0.9330 & 2.4392 & 4.5239 & 0.0224 & 0.9588 \\
\hline HM & 1.8539 & 3.9731 & 0.0203 & 0.9658 & 2.0218 & 4.6953 & 0.0241 & 0.9299 & 2.4022 & 4.5252 & 0.0224 & 0.9588 \\
\hline
\end{tabular}

Table 4

Comparison of methods according to mean speed, standard deviation and power density for Lomé site

\begin{tabular}{|c|c|c|c|c|c|c|}
\hline \multirow[t]{2}{*}{ Methods } & \multicolumn{2}{|l|}{ Mean speed } & \multicolumn{2}{|c|}{ Standard deviation } & \multicolumn{2}{|l|}{ Mean power density } \\
\hline & $\begin{array}{l}\text { Predicted } \\
(\mathrm{m} / \mathrm{s})\end{array}$ & $\begin{array}{l}\text { RPE } \\
(\%)\end{array}$ & $\begin{array}{l}\text { Predicted } \\
(\mathrm{m} / \mathrm{s})\end{array}$ & $\begin{array}{l}\text { RPE } \\
(\%)\end{array}$ & $\begin{array}{l}\text { Predicted } \\
\left(\mathrm{W} / \mathrm{m}^{2}\right)\end{array}$ & $\begin{array}{l}\text { RPE } \\
(\%)\end{array}$ \\
\hline GPM & 2.8816 & -18.3389 & 1.5804 & -22.1324 & 29.5832 & -46.1798 \\
\hline MLM & 3.7025 & 4.9246 & 1.9088 & -5.9556 & 58.4754 & 6.3835 \\
\hline EPFM & 3.5287 & 0.0000 & 1.9461 & -4.1173 & 54.6857 & -0.5111 \\
\hline EMJ & 3.5287 & 0.0000 & 2.0051 & -1.2091 & 56.7331 & 3.2137 \\
\hline EML & 3.5312 & 0.0708 & 2.0065 & -1.1392 & 56.8536 & 3.4329 \\
\hline MOM & 3.5286 & -0.0018 & 1.9442 & -4.2108 & 54.6198 & -0.6310 \\
\hline $\mathrm{HM}$ & 3.5287 & 0.0000 & 1.9751 & -2.6869 & 55.6799 & 1.2975 \\
\hline
\end{tabular}

Table 5

Comparison of methods according to mean speed, standard deviation and power density for Accra site

\begin{tabular}{|c|c|c|c|c|c|c|}
\hline \multirow[t]{2}{*}{ Methods } & \multicolumn{2}{|c|}{ Mean speed } & \multicolumn{2}{|c|}{ Standard deviation } & \multicolumn{2}{|c|}{ Mean power density } \\
\hline & $\begin{array}{l}\text { Predicted } \\
(\mathrm{m} / \mathrm{s})\end{array}$ & $\begin{array}{l}\text { RPE } \\
(\%)\end{array}$ & $\begin{array}{l}\text { Predicted } \\
(\mathrm{m} / \mathrm{s})\end{array}$ & $\begin{array}{l}\mathrm{RPE} \\
(\%)\end{array}$ & $\begin{array}{c}\text { Predicted } \\
\left(\mathrm{W} / \mathrm{m}^{2}\right)\end{array}$ & $\begin{array}{l}\mathrm{RPE} \\
(\%)\end{array}$ \\
\hline GPM & 3.5485 & -14.7054 & 2.1111 & -4.7292 & 61.2424 & -25.5209 \\
\hline MLM & 4.4471 & 6.8933 & 1.9868 & -10.3399 & 88.1104 & 7.1543 \\
\hline EPFM & 4.1603 & 0.0000 & 2.1162 & -4.5016 & 81.7690 & -0.5577 \\
\hline EMJ & 4.1603 & 0.0000 & 2.1925 & -1.0576 & 85.0041 & 3.3766 \\
\hline EML & 4.1628 & 0.0587 & 2.1938 & -0.9996 & 85.1538 & 3.5587 \\
\hline MOM & 4.1603 & -0.0005 & 2.1143 & -4.5853 & 81.6918 & -0.6516 \\
\hline $\mathrm{HM}$ & 4.1603 & 0.0000 & 2.1536 & -2.8125 & 83.3325 & 1.3439 \\
\hline
\end{tabular}

For the mean wind speed, only the graphical method presented a remarkable error. All the other methods have shown a good accuracy. Finally, we note that the Weibull parameters estimated by HM, EMJ and EPFM are adequate for predicting the average value with relative percent error (RPE) lower than $0.0301 \%$ in the three study sites.

The standard deviation analysis permits similar conclusion, in spite of MLM, which predicted the standard deviation with relative percent error (RPE) greater than $10 \%$ in Accra and Cotonou sites. Thus the EMJ, EML and HM methods are most appropriate to predict the standard deviation of wind speeds at the three sites.
For the mean power density, only the graphical method presented a remarkable error. All the other methods have shown a good accuracy. But the power densities calculated from Weibull parameters estimated by EPFM, MOM and $\mathrm{HM}$ best predicts the power densities with relative percent error (RPE) lower than $1.3 \%$ in the three study sites.

\subsection{Monthly Analysis}

In this part, the obtained results on the monthly basis evaluation are presented. Figures 7 through 12 illustrate the average of monthly values of $\mathrm{C}$ and $\mathrm{K}$ for Lomé, Accra and Cotonou sites, respectively. It is seen that for all sites 
Citation: Guenoukpati, A., Salami, A.A., Kodjo, M.K., and Napo, K. (2020) Estimating Weibull Parameters for Wind Energy Applications Using Seven Numerical Methods: Case studies of Three Coastal Sites in West Africa. Int. Journal of Renewable Energy Development, 9(2),217-226, doi: 10.14710/ijred.9.2.217-226

$\mathrm{P}$ a g e $\mid 224$

the values of $\mathrm{C}$ parameter from all methods are very close to each other and only some major differences are noticed for GPM. Nevertheless, the values of $\mathrm{K}$ parameter for GPM, EMJ, EML, EPFM, MOM and HM methods are in the same range for all months while for the MLM methods the $\mathrm{K}$ takes higher values compared to other methods. These differences in $\mathrm{K}$ and $\mathrm{C}$ values for the methods lead to larger differences in the calculated values of wind speed average, standard deviation and wind power density.

Table 6

Comparison of methods according to mean speed, standard deviation and power density for Cotonou site

\begin{tabular}{cccccccc}
\hline & \multicolumn{2}{c}{ Mean speed } & \multicolumn{2}{c}{ Standard deviation } & & \multicolumn{3}{c}{ Mean power density } \\
\cline { 2 - 6 } Methods & $\begin{array}{c}\text { Predicted } \\
(\mathrm{m} / \mathrm{s})\end{array}$ & $\begin{array}{c}\text { RPE } \\
(\%)\end{array}$ & $\begin{array}{c}\text { Predicted } \\
(\mathrm{m} / \mathrm{s})\end{array}$ & $\begin{array}{c}\text { RPE } \\
(\%)\end{array}$ & \multicolumn{2}{c}{$\begin{array}{c}\text { Predicted } \\
\left(\mathrm{W} / \mathrm{m}^{2}\right)\end{array}$} & $\begin{array}{c}\text { RPE } \\
(\%)\end{array}$ \\
\hline GPM & 3.0520 & -23.9213 & 1.5279 & -15.7874 & 31.7458 & -49.8960 \\
MLM & 4.2210 & 5.2199 & 1.5852 & -12.6319 & 66.0511 & 4.2477 \\
EPFM & 4.0237 & 0.3018 & 1.7375 & -4.2396 & 63.4089 & 0.0776 \\
EMJ & 4.0237 & 0.3018 & 1.7825 & -1.7547 & 64.7902 & 2.2576 \\
EML & 4.0247 & 0.3269 & 1.7830 & -1.7301 & 64.8388 & 2.3344 \\
MOM & 4.0237 & 0.3027 & 1.7362 & -4.3080 & 63.3730 & 0.0208 \\
HM & 4.0116 & 0.0000 & 0.1791 & 1.9469 & 64.2653 & 1.4293 \\
\hline
\end{tabular}

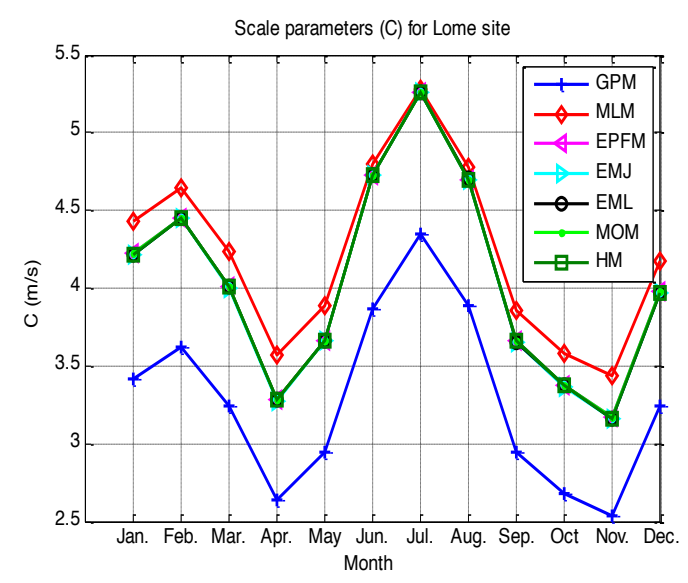

Fig. 7 Average of monthly values of C $(\mathrm{m} / \mathrm{s})$ for Lomé

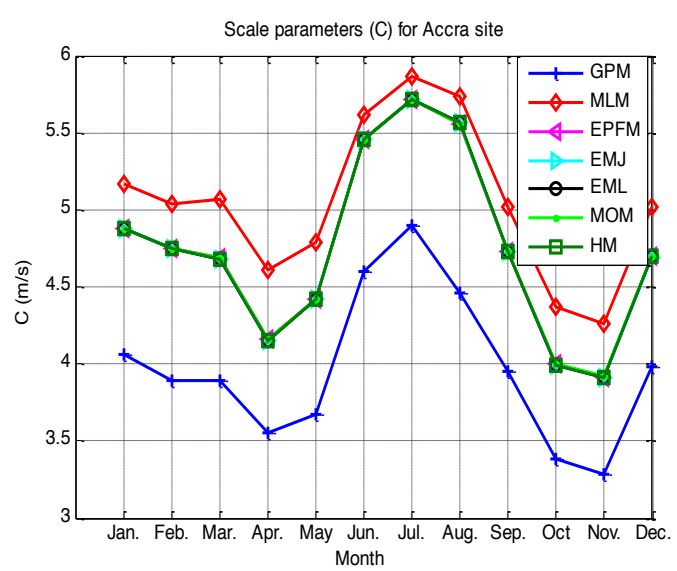

Fig. 8 Average of monthly values of $\mathrm{C}(\mathrm{m} / \mathrm{s})$ for Accra
In order to provide a month by month comparison and assessment between measured and estimated values of wind speed average, standard deviation and wind power, a statistical frequency analysis was performed using the RPE indicator. The results of Tables 4, 5 and 6 show that only EPFM, EMJ, EML, MOM and HM methods are recommended to estimate Weibull parameters to predict the monthly average wind speeds, the monthly standard deviations of wind speeds and monthly power densities with RPE lower than $10 \%$ on Lomé site.

Therefore EPFM, EMJ, EML, MOM and HM methods are recommended to estimate Weibull parameters to predict the monthly average wind speeds, the monthly standard deviations of wind speeds and monthly power densities with RPE lower than $10 \%$ on Accra site.

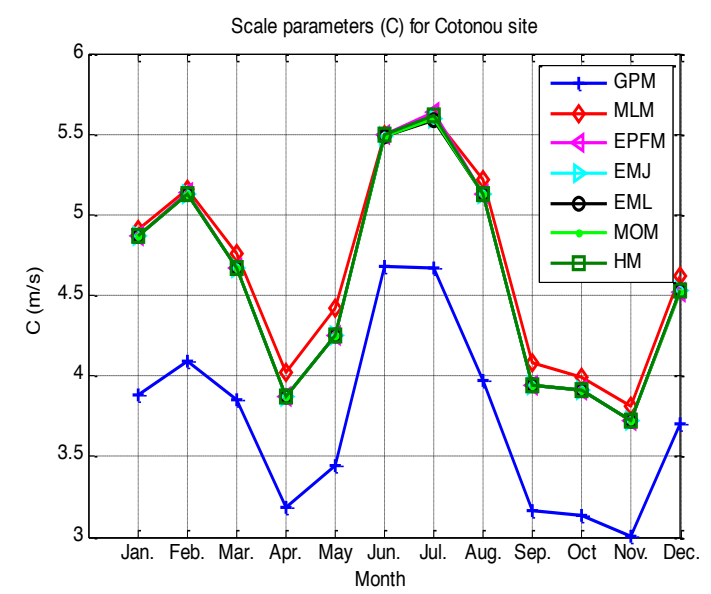

Fig. 9 Average of monthly values of C $(\mathrm{m} / \mathrm{s})$ for Cotonou 


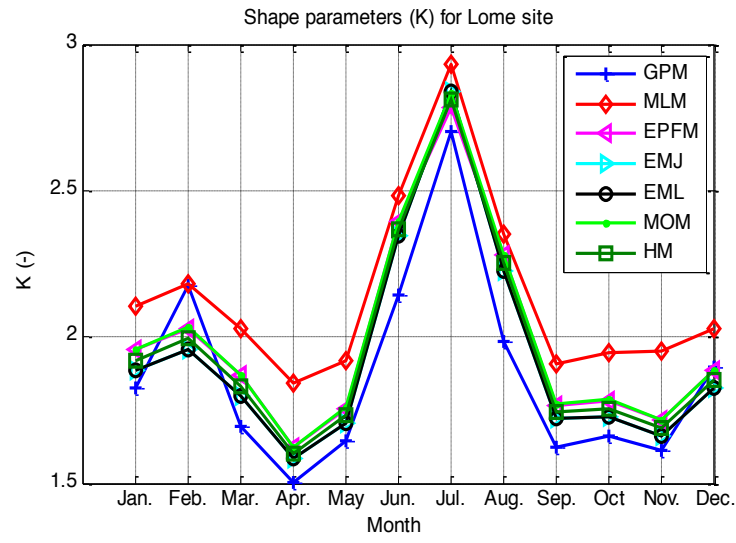

Fig. 10 Average of monthly values of K (-) for Lomé

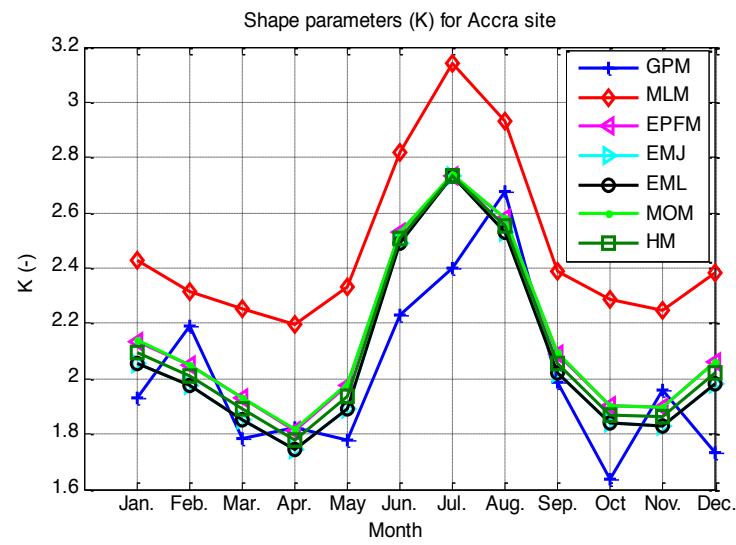

Fig. 11 Average of monthly values of K (-) for Accra

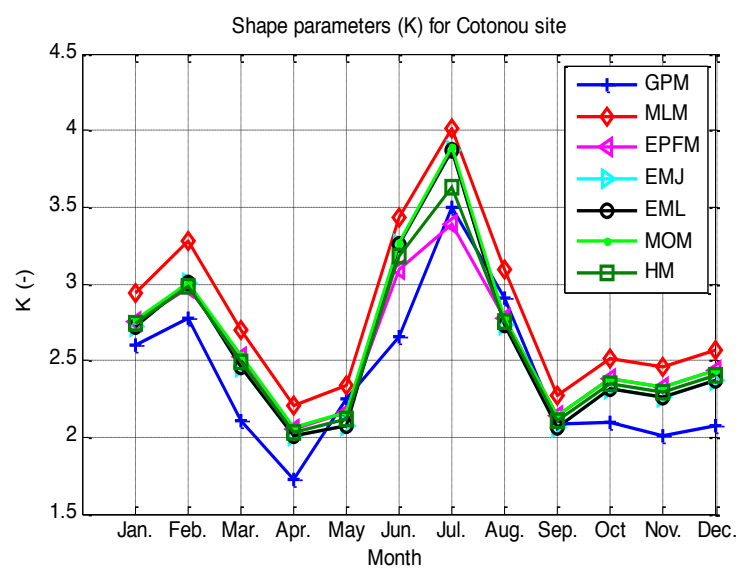

Fig. 12 Average of monthly values of K (-) for Cotonou

According to above results, we notice that only EPFM, EMJ, EML, MOM, MLM and HM methods are recommended to estimate Weibull parameters to calculate average wind speeds, with RPE lower than $10 \%$ on Cotonou site for all the twelve months. Additionally to calculate the monthly standard deviations and wind power densities on the site of Cotonou, it is preferable to use the Weibull parameters estimated by EPFM, EMJ, EML and MOM.

Among the calculated parameters (mean of wind speed, standard deviation of wind speed and wind power density), wind power density plays a critical role in wind energy applications. The wind power density portrays the potential of wind resources and to describe the amount of wind energy at various wind speed values in a particular location. The knowledge of wind power density is also useful for evaluating the performance of wind turbines and choosing the optimal wind turbines. Wind power density indicates the level of energy available that can be converted into electricity by using wind turbines. That is why the result of our analysis focuses on calculations of monthly power densities on the three sites using the six methods.

\section{Conclusion}

The purpose of this article is to determine a suitable method for estimating Weibull parameters for wind energy applications on three costal sites in West Africa. For this, six methods often used in the literature are applied to wind speed data collected at each site. These are: the graphical method (GPM), maximum likelihood method (MLM) moment method (MOM), energy pattern factor method (EPFM), empirical method of Justus (EMJ) and empirical method of Lysen (EML). Moreover, a hybrid method derived from EPFM and EMJ is proposed to also determine Weibull distribution function parameters. The results reveal that only GPM does not yield acceptable adjustment errors on the three sites and often the MLM has the lowest error adjustment of the distribution histogram of wind speeds at the three sites.

The Weibull parameters estimated by the methods EMJ, EML, EPFM, MOM and HM are recommended for predicting wind speed average, standard deviation and mean wind power density on Lomé, Accra and Cotonou sites located in West Africa. Thus for wind energy applications for costal sites in West Africa, we recommend using:

- MLM method to estimate Weibull parameters that best fit the histogram of wind frequency distributions;

- HM, EMJ, EML, EPFM, MLM, or MOM method to estimate Weibull parameters for better prediction of mean wind speeds, the standard deviation and mean wind power density.

\section{Acknowledgments}

The authors want to thank the University of Lomé for providing enabling environment during the research.

\section{References}

Ajavon, A. S. A., Salami, A. A., Kodjo, M. K., \& Bédja, K.-S. (2015). Comparative characterization study of the variability of wind energy potential by wind direction sectors for three coastal sites in Lomé, Accra and Cotonou. Journal of Power Technologies, 95(2), 134-142.

Akdağ, S. A., \& Dinler, A. (2009). A new method to estimate Weibull parameters for wind energy applications. Energy Conversion and Management, 50(7), 1761-1766.

Arslan, T., Bulut, Y. M., \& Yavuz, A. A. (2014). Comparative study of numerical methods for determining Weibull parameters for wind energy potential. Renewable and Sustainable Energy Reviews, 40, 820-825.

Ayenagbo, K., Kimatu, J. N., \& Rongcheng, W. (2011). A model for a sustainable energy supply strategy for the socialeconomic development of Togo. Journal of Economics and 
International Finance, 3(6), 387-398.

Azad, A., Rasul, M., \& Yusaf, T. (2014). Statistical diagnosis of the best weibull methods for wind power assessment for agricultural applications. Energies, 7(5), 3056-3085.

Brew-Hammond, A., \& Kemausuor, F. (2009). Energy for all in Africa?to be or not to be?! Current Opinion in Environmental Sustainability, 1(1), 83-88.

Celik, A. N. (2003). Energy output estimation for small-scale wind power generators using Weibull-representative wind data. Journal of Wind Engineering and Industrial Aerodynamics, 91(5), 693-707.

Chang, T. P. (2011). Performance comparison of six numerical methods in estimating Weibull parameters for wind energy application. Applied Energy, 88(1), 272-282.

Deichmann, U., Meisner, C., Murray, S., \& Wheeler, D. (2011). The economics of renewable energy expansion in rural SubSaharan Africa. Energy Policy, 39(1), 215-227.

Dorvlo, A. S. S. (2002). Estimating wind speed distribution. Energy Conversion and Management, 43(17), 2311-2318.

Genc, A., Erisoglu, M., Pekgor, A., Oturanc, G., Hepbasli, A., \& Ulgen, K. (2005). Estimation of wind power potential using Weibull distribution. Energy Sources, 27(9), 809-822.

Jamieson, P. D., Porter, J. R., \& Wilson, D. R. (1991). A test of the computer simulation model ARCWHEAT1 on wheat crops grown in New Zealand. Field Crops Research, 27(4), 337350 .

Jowder, F. A. L. (2009). Wind power analysis and site matching of wind turbine generators in Kingdom of Bahrain. Applied Energy, 86(4), 538-545.

Justus, C. G., Hargraves, W. R., Mikhail, A., \& Graber, D. (1978). Methods for estimating wind speed frequency distributions. Journal of Applied Meteorology, 17(3), 350353.

Keyhani, A., Ghasemi-Varnamkhasti, M., Khanali, M., \& Abbaszadeh, R. (2010). An assessment of wind energy potential as a power generation source in the capital of Iran, Tehran. Energy, 35(1), 188-201.

Leung, D. Y. C., \& Yang, Y. (2012). Wind energy development and its environmental impact: A review. Renewable and Sustainable Energy Reviews, 16(1), 1031-1039.

Li, M.-F., Tang, X.-P., Wu, W., \& Liu, H.-B. (2013). General models for estimating daily global solar radiation for different solar radiation zones in mainland China. Energy Conversion and Management, 70, 139-148.

Lu, L., Yang, H., \& Burnett, J. (2002). Investigation on wind power potential on Hong Kong islands?an analysis of wind power and wind turbine characteristics. Renewable
Energy, 27(1), 1-12.

Mentis, D., Hermann, S., Howells, M., Welsch, M., \& Siyal, S. H. (2015). Assessing the technical wind energy potential in Africa a GIS-based approach. Renewable Energy, 83, 110125.

Mohammadi, K., Alavi, O., Mostafaeipour, A., Goudarzi, N., \& Jalilvand, M. (2016). Assessing different parameters estimation methods of Weibull distribution to compute wind power density. Energy Conversion and Management, 108, 322-335.

Mostafaeipour, A., Sedaghat, A., Dehghan-Niri, A. A., \& Kalantar, V. (2011). Wind energy feasibility study for city of Shahrbabak in Iran. Renewable and Sustainable Energy Reviews, 15(6), 2545-2556.

Rocha, P. A. C., de Sousa, R. C., de Andrade, C. F., \& da Silva, M. E. V. (2012). Comparison of seven numerical methods for determining Weibull parameters for wind energy generation in the northeast region of Brazil. Applied Energy, 89(1), 395-400.

Safari, B. (2011). Modeling wind speed and wind power distributions in Rwanda. Renewable and Sustainable Energy Reviews, 15(2), 925-935.

Salami, Adekunlé Akim, Ajavon, A. S. A., Kodjo, M. K., Ouedraogo, S., \& Bédja, K.-S. (2018). The Use of Odd and Even Class Wind Speed Time Series of Distribution Histogram to Estimate Weibull Parameters. International Journal of Renewable Energy Development, 7(2), 139-150.

Salami, Akim A, Ajavon, A. S. A., Kodjo, M. K., \& Bedja, K.-S. (2016). Evaluation of Wind Potential for an Optimum Choice of Wind Turbine Generator on the Sites of Lomé, Accra, and Cotonou Located in the Gulf of Guinea. International Journal of Renewable Energy Development, $5(3)$.

Salami, Akim Adekunle, Ajavon, A. S. A., Kodjo, M. K., \& Bedja, K.-S. (2013). Contribution to improving the modeling of wind and evaluation of the wind potential of the site of Lome: Problems of taking into account the frequency of calm winds. Renewable Energy, 50, 449-455.

Seguro, J. V, \& Lambert, T. W. (2000). Modern estimation of the parameters of the Weibull wind speed distribution for wind energy analysis. Journal of Wind Engineering and Industrial Aerodynamics, 85(1), 75-84.

Stevens, M. J. M., \& Smulders, P. T. (1979). The estimation of the parameters of the Weibull wind speed distribution for wind energy utilization purposes. Wind Engineering, 132-145. 